\title{
An analysis of urban renewal decision-making in China from the perspective of transaction costs theory: the case of Chongqing
}

\author{
Taozhi Zhuang $^{1}$ (D) $\cdot$ Queena K. Qian ${ }^{1} \cdot$ Henk J. Visscher ${ }^{1} \cdot$ Marja G. Elsinga ${ }^{1}$
}

Received: 23 May 2019 / Accepted: 30 January 2020 / Published online: 18 February 2020

(c) The Author(s) 2020

\begin{abstract}
In China, there is a growing number of urban renewal projects due to the rapid growth of the economy and urbanization. To meet the needs of urban development, urban renewal requires a sound decision-making approach involving various stakeholder groups. However, current urban renewal decision-making is criticized for poor efficiency, equity, and resulting in many unintended adverse outcomes. It is claimed that high-level transaction costs (e.g., a great deal of time spent on negotiation and coordination) are the factors hidden behind the problems. However, few studies have analyzed urban renewal decisionmaking in a transaction costs perspective. Using the case of Chongqing, this paper aims at adopting transaction costs theory to understand the administrative process of urban renewal decision-making in China. This research focuses on four key stakeholder groups: municipal government, district government, local administrative organizations, and the consulting parties. A transaction costs analytical framework is established. First, the decision-making stages of urban renewal and involved key stakeholder groups are clarified. Second, the transactions done by different stakeholder groups in each stage is identified, thus to analyze what types of transaction costs are generated. Third, the relative levels of transaction costs among different stakeholder groups were measured based on the interview. The empirical analysis reveals how transaction costs occur and affect urban renewal decision-making. Finally, policy implications were proposed to reduce transaction costs in order to enhance urban renewal.
\end{abstract}

Keywords Urban renewal · Decision making $\cdot$ Transaction costs $\cdot$ China

Taozhi Zhuang

t.zhuang@tudelft.nl

Queena K. Qian

k.qian@tudelft.nl

Henk J. Visscher

H.J.Visscher@tudelft.nl

Marja G. Elsinga

M.G.Elsinga@tudelft.nl

1 Faculty of Architecture and the Built Environment, Delft University of Technology, P.O.

Box 5043, 2600 GA Delft, The Netherlands 


\section{Introduction}

Since the late $1970 \mathrm{~s}$, the reform and opening-up policy have brought about the rapid growth of the economy and urban population in China (Qian 2010). However, under this background, the country faces continuous challenges in meeting the rigid demand for more high-quality buildings and neighborhoods in the urban area. Urban renewal becomes a national strategy and has been widely adopted in most Chinese cities. Today, urban renewal is becoming a critical approach to improve our urban life quality and will keep playing this vital role shortly (Chen et al. 2008; Shen et al. 2013). It rehabilitates the urban areas through physical change and other comprehensive plans to meet the requirement of urban development (Lee and Chan 2008; Zhuang et al. 2019).

Although urban renewal has made significant contributions in urban development, there are still many problems surrounded by, including conflicts between stakeholders, loss of social network and urban culture, impact on the living environment, and other unintended consequences (Yau and Chan 2008; Zhuang et al. 2017). Since urban renewal is high-input, irreversible public projects, decision-making plays a dominant role in project success (Liu et al. 2017; Zhou et al. 2017). Many studies show that how the decisions were made is one of the major causes of the above problems (Juan et al. 2010; Maginn 2007; Mayer et al. 2005; Wang et al. 2014). In China, urban renewal decision-making is government-led but strongly affected by the interaction between different stakeholders in the complex administrative process (Juan et al. 2010; Zhou et al. 2017). The interaction reflects in the transfer of information or knowledge between stakeholders, which would incur much transaction costs (Hastings and Adams 2005).

Arrow (1969) firstly defined "transaction costs" as the costs of running an economic system, including exclusion costs and costs of communication, and the costs of disequilibrium. In short, transaction costs can be seen as all costs other than the production costs (Chung 1994). Contrary to the latter, transaction costs differ for resource allocation and changes with the economic systems (Arrow 1969). Based on this, transaction costs are considered as the costs of an institution in essential (Cheung 1989). It is also supported by North (1990), who claimed that transaction costs are the sources of power for social, economic, and political institutions. Transaction costs are certain to emerge since there is unavoidably bounded rationality, opportunism and deficient information, and the levels and characteristics of transaction costs vary in different institutions (Buitelaar 2004).

Although the transaction costs have been adopted in many fields, its introduction into land development is relatively new. This has brought about a new thought to explore the theory and practice in this context. Alexander (2001) offers a conceptual model by adopting transaction costs theory to analyze different governance structures in land use planning and development. Buitelaar (2004) proposes a framework to identify the transaction costs in the land development process and compare the user rights regime in the Dutch context. Aiming at assessing the institutional efficiency of different governance structures, Cho (2011) applies transaction costs theory in analyzing the housing redevelopment process in Korea. Moreover, to explore the institutional barriers in urban village redevelopment in China, Lai and Tang (2016) consider the redevelopment as a series of transactions, thus to analyze the role of institutions. Although there are increasing studies on land development concerning transaction costs, the adoption of this theory is mainly focusing on the implementation process. The explorations of the early stage (decision-making) are quite limited. Moreover, there exist unique culture and institutions in China, including the stakeholders' awareness on public projects, state-ownership of urban land, the strong top-down 
administrative approach, etc. (Enserink and Koppenjan 2007; Li et al. 2012; Tang et al. 2008). These are different from China's western counterparts. Due to the uniqueness, it is not feasible to directly learn the knowledge out of Chinese contexts. Based on the above reasons, an in-depth analysis of current decision-making of urban renewal given transaction costs theory is vital to better understand the problems in the Chinese context, thus to make improvements and deal with the barriers that occurred in the process.

Consequently, this paper aims at adopting transaction costs theory to understand the current administrative process of urban renewal decision-making in China. The following research questions are answered: what is the administrative process of urban renewal decision-making? What are the transaction costs borne by different key stakeholder groups in each decision-making stage? Moreover, what are the levels of different transaction costs given to each key stakeholder group? Chongqing was selected as the case city for its representativeness of southwest China and a large number of urban renewal projects. The remainder of this paper was structured as follows. First, it reviewed on the background of transaction costs and urban renewal decision-making in China. Then, it described the analytical framework, case area, and data collection. Following this, this paper analyzed the transaction costs borne by different key stakeholder groups in urban renewal decisionmaking. At last, discussion and conclusions are presented.

\section{Urban renewal decision-making and transaction costs}

\subsection{Urban renewal decision-making and key stakeholder groups}

The decision making of urban renewal is not just a 'single-decision', which determines whether to do it or not. It considers the urban development, living environment, renewal area selection, timing, mode, social risks, compensation, etc. through a systematic process (Jiang et al. 2012; Tang 2015; Zhuang et al. 2019). In this research, the decision-making of urban renewal is defined as the formal administrative process starting from project application, and before housing expropriation and demolition. In China, the detailed decisionmaking process differs from one city to another, but based on literature and the authors' knowledge, it can be categorized into four major stages in general, namely preparation stage, project planning stage, compensation planning stage, and final agreement stage (Liao 2013; Tian 2009; Yang 2007). In the preparation stage, preliminary information searching is conducted to list neighborhoods which are probably brought under an urban renewal plan. Then, in the second stage, a comprehensive project plan will be made, including the selection of renewal area, time arrangement, renewal mode, financing arrangement, etc. In the third stage, a compensation plan of housing expropriation in the designated urban renewal area will be made. In the final stage, the compensation plan will be announced to collect public opinions and reach final agreements between government sectors and the insitu residents. If the agreement cannot be reached, further negotiation or plan modification will be conducted.

In China, there exist many stakeholder groups participating in the urban renewal decision-making process, including the different levels of governments, consulting parties, in-situ residents, and other organizations (Zhuang et al. 2019). The government plays a dominant role in the administration process of decision-making. In many studies, the government is considered as one stakeholder, but in practice, the roles of government differ from one administrative level to another (Tang 2015; Yi et al. 2017). Based on the 
authors' previous research, taking Chongqing as an example, three administrative levels of governments are the main bodies in administrative activities of urban renewal decisionmaking (Zhuang et al. 2019). The primary role of the municipal government is to guide and oversee the work of the district government and to approve the relevant plans. District governments hold the strongest power in decision-making and involve in the whole administrative process. The local administrative organizations are the grassroots-level governments, which consist of two sub-levels (sub-district administrative offices and neighborhood committees). They are mainly responsible for the groundwork (e.g., field investigation, policy advocacy) to support the work of the district government. Consulting parties, including scholars, planning/design agency, real estate appraisal agency, building safety appraisement agency, etc., are the stakeholder group who conducts professional research and offer consulting services to the governments in the decision-making process (Zhuang et al. 2017). Different consulting parties deeply involve in diverse administrative activities to support the projects. The in-situ residents are also an important stakeholder in urban renewal, but their participation is relatively passive in decision-making. In view of administration process, in-situ residents cannot exert their influence on decision-making in an initiative way (Zhuang et al. 2019). In addition, developers also play an important role. However, in accordance with current laws and regulations, market power is not allowed to involve in decision-making. Therefore, in formal administrative process, there is no channel for developers to involve before project implementation (Zhuang et al. 2019). Since urban renewal is top-down public projects in China, administrative power is dominantly influential to the decision-making (Li et al. 2018; Yi et al. 2017; Zhuang et al. 2019). To better explore the urban renewal decision-making, this paper selects the stakeholder groups which highly and actively participate in administrative activities in decision-making as the focuses. Therefore, based on these criteria, four key stakeholder groups are focused on: municipal government, district government, local administrative organizations, and the consulting parties.

\subsection{Definition and types of transaction costs}

The transaction refers not only to the goods or services but also includes the transfer of information, knowledge, and ideas (Shahab et al. 2018). Buitelaar (2004) defines the transaction costs as the costs for increasing the availability of information and reducing uncertainty brought by the institutions. Transaction costs are one of the significant elements in the analysis of all public policies and projects (McCann 2013; Shahab et al. 2018). In the facet of transaction costs, the series activities can be seen as numbers of transaction items which generate different levels of transaction costs (McCann 2013). Transaction costs exert influence on the efficiency and the outcome of projects. The level of the influence varies since the stakeholders have divergent perceptions and behaviors; the interactions between them are also diverse (Coggan et al. 2013). Taking transaction costs into account can enhance the efficiency and equity of policy instruments, perceive unintended consequences, design more practical policy instruments, and provide the basis to include various aspects of the institutional environment (Garrick et al. 2013; McCann 2013; Qian et al. 2012; Shahab et al. 2018).

Studies have been done to probe the typologies of transaction costs. There are mainly two categorization methods. One is based on the time the transaction costs emerged. For example, Shahab et al. (2018) categorize transaction costs as ex-ante, ongoing, and expost costs according to three planning steps: preparation, implementation, and revision. 
The other categorization is given the way to bear the costs (Michaelowa and Jotzo 2005; Mundaca et al. 2013; Qian et al. 2015). In this category, the types of transaction costs are listed according to the relevant references in the field of land development, which is shown in Table 1. To summarize, transaction costs include information searching costs, research costs, coordination/negotiation costs, monitoring costs, approval costs.

\subsection{Transaction determinants in the context of urban renewal decision-making}

Each transaction has its determinants that strongly affect the magnitude and distribution of transaction costs. According to Williamson (1985), the determinants of transactions can be concluded as three key dimensions, which are asset specificity, uncertainty, and timing. In urban renewal decision-making, these three dimensions have specific characteristics.

\subsubsection{Asset specificity}

Asset specificity refers that the transaction of an asset that cannot be easily redeployed and substituted. Because the transaction-specific investments in capital, information, etc. for the particular transactions are the sunk costs, which have no or little value outside of the particular transaction. Since each urban renewal project is unique in location, neighborhood environment, building conditions, cultural value, property ownership, etc., the decision made for one project in particular. Thus, the investments cannot easily be reinvested into the decision-making process of another project. According to Williamson (1991), asset specificity can be categorized into four types: site-specificity (particular sites of an asset), physical asset specificity (specific inputs and actions), human asset specificity (specialized knowledge and skills), and dedicated asset (discrete investment in general production for particular transaction, such as expanding production lines for a specific buyer).

In urban renewal decision-making, the transaction is mainly about information or knowledge rather than physical productions. Therefore, asset specificity can be categorized into three types: site-specificity, information specificity, and resident specificity. Site specificity means the specific site of the designated urban renewal area (buildings/ neighborhoods). The size, location, building conditions, neighborhood environment, etc. of a site strongly affect decisions and causes lots of research costs. Information specificity adopts the concept of the above-mentioned human asset specificity. It represents the specific information or knowledge required in urban renewal decision-making, such as public voice, existing planning, and policies. Collecting relevant information induces information searching costs. Resident specificity comes from the concept of physical asset specificity,

Table 1 Type of transaction costs in field of land development according to relevant literatures

\begin{tabular}{|c|c|c|c|c|c|}
\hline Types & $\begin{array}{l}\text { Shahab et al. } \\
(2018)\end{array}$ & $\begin{array}{l}\text { Buitelaar } \\
(2004)\end{array}$ & Cho (2011) & $\begin{array}{l}\text { Hastings and } \\
\text { Adams (2005) }\end{array}$ & $\begin{array}{l}\text { Lai and } \\
\text { Tang } \\
(2016)\end{array}$ \\
\hline Information searching costs & $\sqrt{ }$ & $\sqrt{ }$ & $\sqrt{ }$ & $\sqrt{ }$ & $\sqrt{ }$ \\
\hline Research costs & $\sqrt{ }$ & $\sqrt{ }$ & & $\sqrt{ }$ & $\sqrt{ }$ \\
\hline Coordination/negotiation costs & $\sqrt{ }$ & $\sqrt{ }$ & $\sqrt{ }$ & $\sqrt{ }$ & $\sqrt{ }$ \\
\hline Approval costs & $\sqrt{ }$ & $\sqrt{ }$ & $\sqrt{ }$ & & \\
\hline Monitoring costs & & $\sqrt{ }$ & & $\sqrt{ }$ & $\sqrt{ }$ \\
\hline
\end{tabular}


but it has its own meaning in urban renewal since the specific inputs and actions are for the in-situ residents. In every urban renewal area, there may be hundreds or thousands of insitu residents with diverse demands. It requires lots of research and coordination/negotiation costs to develop the detailed compensation plan for each residential unit and achieve the agreements on it.

\subsubsection{Uncertainty}

Uncertainty is the second dimension of transaction determinants. The source of uncertainty is strongly related to the asymmetric information about the transaction, the perceptions and actions of the stakeholders, and the unpredictable issues brought by the relevant natural, organizational, and institutional environment (Mettepenningen and Van Huylenbroeck 2009). Based on this, scholars conclude three types of uncertainty (Coggan et al. 2010; Fan et al. 2018; Williamson 1985). The first one is the uncertainty of nature in the future state. It means that the conditions, such as natural disaster, may bring substantial restriction in the physical environment. The second one refers to the lack of clarity of the actions of whether stakeholders should do or not, because of the poorly-specified policies, regulations, contracts, etc. The third type is related to the behavior of stakeholders attributed to opportunism since there always exists distrust between them.

In the decision-making of urban renewal, uncertainty can lead to extra works and more communications for all stakeholder groups throughout the process. Based on the definition, there are two types of uncertainty in urban renewal decision-making, namely behavior uncertainty, and institutional uncertainty. The former is the result of opportunism. It causes inefficiency in communication and cooperation. The latter is created by the existing institution, which leads to extra works in the administrative process. Since the natural conditions (e.g., thunderstorm, earthquake) are not relevant to the decision-making process, those elements are not considered in this research.

\subsubsection{Timing}

The timing dimension is also a critical transaction determinant. In one project, long-lasting transactions incur much more and complicated barriers such as bilateral monopoly and opportunism (Cho 2011; Coggan et al. 2010; Williamson 1985). When there are recurring transactions between the same participants, transaction costs can be reduced through transferring the past information and knowledge, to the newly happened transaction (Fan et al. 2018). In urban renewal decision-making, to reduce transaction costs, it requires to contain more transferable experience. Therefore, the transferability of a transaction is adopted to measure in what level the transaction costs can be trimmed down. In one urban renewal project, it can also be reflected in the time spend on a transaction.

\section{Research methodology}

\subsection{Analytical framework}

Based on the literature review on urban renewal decision-making and transaction costs theory, an analytical framework is established, which is shown in Fig. 1. This research selects Chongqing as the case study area in China by using the analytical framework. 


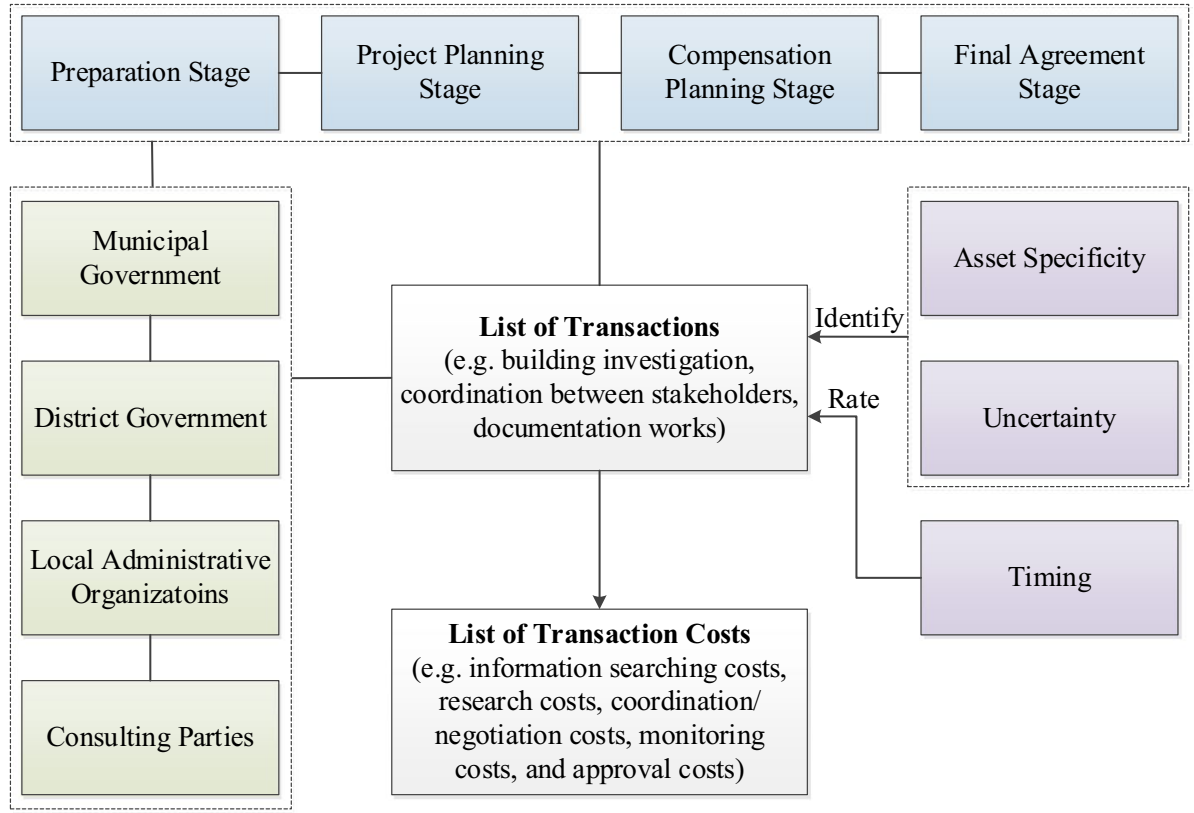

Decision-Making Stage

Stakeholder Groups

Transaction Determinants

Fig. 1 Analytical framework

This framework consists of three steps. In the first step, the detailed administrative process and involved stakeholder groups in each decision-making stage are clarified.

The second step aims at identifying the transaction costs borne by different stakeholder groups in each urban renewal decision-making stage. Based on the transaction determinants "asset specificity" and "uncertainty," what are the transactions that emerged in each stage will be identified. Since it is impossible to reveal all the separate detailed transactions in every project, the simplification of transaction items is adopted. In this research, all the transactions are identified on an aggregated level by equating them with kinds of activities in decision-making. For example, "carefully selecting professional service providers" is one kind of activity. It includes the work of contact between sectors, qualification deliberation, tender evaluation, documentation, contracting, etc. It is unnecessary and impossible to list every single work, respectively. Instead, "carefully selecting professional service providers" is used to represent the relevant works and considered as one transaction. According to the identified transaction, what types of transaction costs are generated can be found out. In urban renewal decision-making, the types of transaction costs can be categorized into information searching costs, research costs, coordination/negotiation costs, monitoring costs, and approval costs, etc., (Buitelaar 2004; Cho 2011; Hastings and Adams 2005; Lai and Tang 2016; Shahab et al. 2018).

The third step aims at measuring the relative levels of transaction costs borne by different stakeholder groups. The transaction determinant "timing" is applied. All transactions are rated by each stakeholder group, respectively, based on the time they spent in general. It can reflect the level of related transaction costs. 


\subsection{Case area}

Chongqing is one of five municipalities directly under the national government. It is a typical sample of urban development in China (Zhou et al. 2017). In the last decades, it has experienced rapid urbanization and economic growth. From 1997 to 2016, the urbanization rate in Chongqing increased from 31.0 to $62.6 \%$, and its annual growth rate of gross domestic product (GDP) is $13.78 \%$ (CSB 2017b). To meet the rigid demand for urban housing and maintain economic growth, in 2008, Chongqing Municipal Government issued a new policy to make urban renewal as one of the key urban development strategies (Liu et al. 2012). From 2010 to 2017, there were 1423.54 ha of urban renewal projects being implemented (CSB 2017a). Featured by the massive urban renewal projects, Chongqing provides many resources and project cases for conducting relevant research.

In Chongqing, the municipality can be divided into 38 sub-divisions, including 26 districts and 12 counties. The central city area, also named the main districts area, is the core of the city and indispensable in the history of urban development. It consists of 9 districts named Yuzhong, Dadukou, Jiangbei, Shapingba, Jiulongpo, Nan'an, Beibei, Yubei, and Banan. The map is shown in Fig. 2. The institution and organizational structure of the above nine districts are similar. In 2016, 191.02 ha of urban renewal projects were planned and implemented in the main districts area, exerting influence on 22,015 households. The main districts area represents one hotspot of urban renewal in Chongqing. Thus, this area is selected for data collection.

\subsection{Data collection}

The semi-structured interviews are applied for data collection in this research. As shown in Table 2, the interviews were conducted with 17 interviewees representing municipal government, district government, local administrative organizations, and consulting parties.

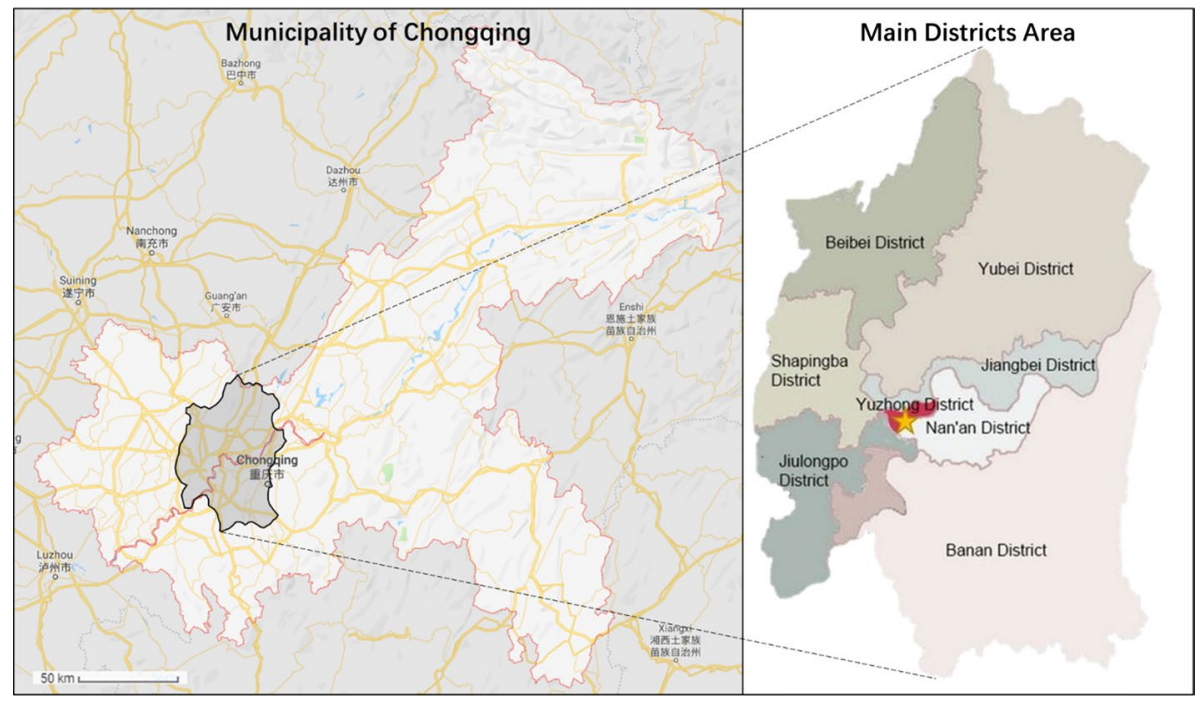

Fig. 2 Map of Chongqing Municipality and its main districts area 


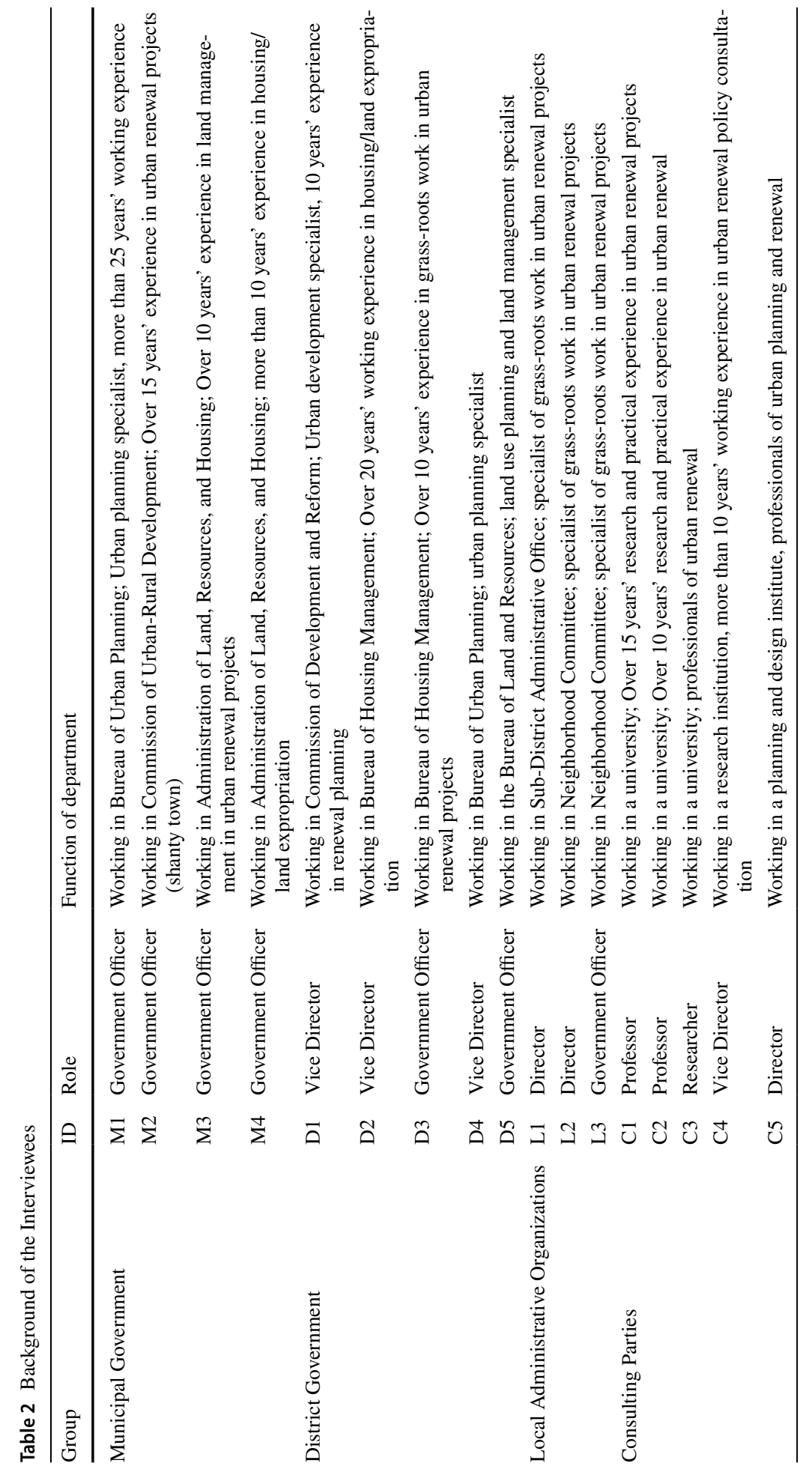


All the selected representatives were professionals who have rich knowledge and practical experience in urban renewal projects in Chongqing.

Prior to the interviews, the authors had listed the works (transactions) that different stakeholder groups need to do in the administrative process of urban renewal decisionmaking according to the literature review and authors' previous research. During the interview, the interviewees were asked (1) to clarify the administrative activities and their roles in decision-making of urban renewal; (2) verify and adjust the list of works (transactions) they need to do, and illustrate the purpose of each work; (3) rate the level of time they spend on each work on a 5-point Likert scale, from $1=$ "very little time" to $5=$ "a great deal of time"; (4) to share more views about the current problems and barriers of urban renewal decision-making beyond the framework, and provide some implications to improve it.

\section{Results}

\subsection{Urban renewal decision-making stages in Chongqing}

Based on the interviews, in the case of Chongqing, there are several administrative activities and stakeholder groups in each decision-making stage being identified, which is shown in Fig. 3.

In the preparation stage, local administrative organizations and sectors in the district government independently search urban areas (neighborhoods/buildings), which may require urban renewal. The information they search consists of two dimensions. One is the rough dilapidated condition of buildings/neighborhoods, and the other one is the demand for urban development.

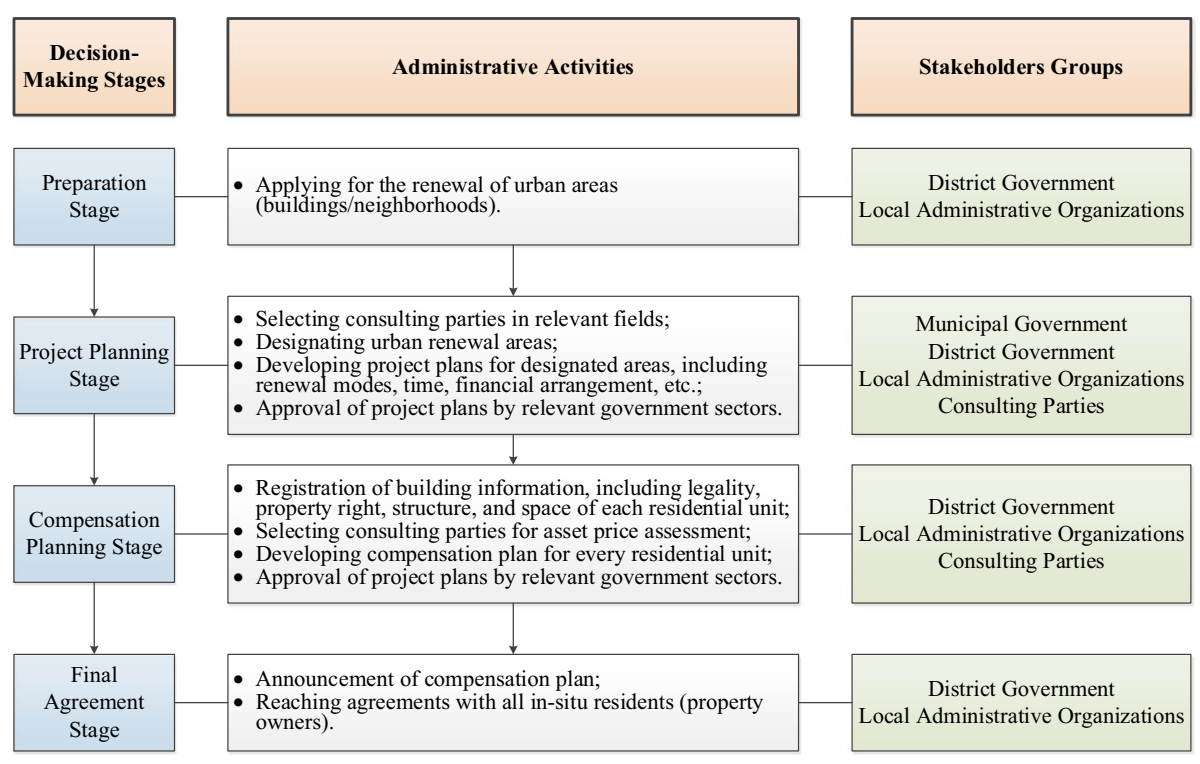

Fig. 3 Whole urban renewal decision-making process in Chongqing, China 
In the project planning stage, municipal government, district government, local administrative organizations, and consulting parties are all participated. To make a comprehensive project plan, district government carefully select consulting parties in the field of urban/community planning, land survey, building safety appraisement, etc. Series work of in-depth research and information searching are cooperatively undertaken all stakeholder groups except municipal government. Based on this, the renewal areas are designated from the application list. Then, the comprehensive project plan, including renewal modes, time, financial arrangement, etc. are developed. The approval of the project plan is a matter for all relevant sectors (urban planning, housing management, land management, etc.) in the district and municipal level. In reaching the approval, there may be rounds of feedbacks taking place between governmental sectors and administrative levels.

In the compensation planning stage, district government, local administrative organizations, and consulting parties exert joint effort to make compensation plans for housing expropriation. Before drafting the plan, investigation of land and property rights, living space, building structure, etc. of each residential unit will be conducted by the district government and local administrative organizations. Then, local administrative organizations will organize a community meeting to select a qualified consultant institution for an asset price assessment. Based on the above works, a detailed compensation plan for every residential unit in the designated urban renewal area is drafted by the district government. The plan will be comprehensively evaluated by other relevant sectors at the district level. Some rounds of feedbacks may also be required to reach the approval.

In the final agreement stage, the district government and local administrative organizations will cooperatively work to reach the final agreement on the compensation plan with in-situ residents (property owners). First, the compensation plan will be announced to the public. Then, lots of work will be done to assess social risks, collect the opinions of in-situ residents, modify the plan, and persuade all in-situ residents to agree on it. Opinion collection-plan modification-persuasion is a feedback loop that cannot be skipped. When all agreements are reached, the whole urban renewal decision-making process is ended.

\subsection{Identification of transactions and transaction costs in each decision-making stage}

According to the transactions' determinants, there are 19 transaction items being evoked in the above four stages being identified, triggering five types of transaction costs. Some transactions occur in only one stage, but others can be found in more than one stage. The list of transactions is validated and consolidated through the interviews. The details in each stage can be seen in Table 3, 4, 5, and 6, respectively.

Table 3 shows the identified transactions in the preparation stage. Although searching for the potential urban renewal area is a key foundation of the whole decision-making, there are only two transactions being evoked.

At the project planning stage in Table 4, there are 13 transactions identified. Both the behavior uncertainty and institutional uncertainty play a vital role. It raises negotiation/ coordination costs and approval costs borne by all stakeholder groups. Moreover, site-specificity is another key determinant of transactions. It raises research costs and information searching costs to comprehensively investigating the buildings and neighborhoods and to ensure the designated projects are not against existing policies and planning.

At the final agreement stage in Table 6, the resident specificity and behavior uncertainty are the major determinants of transactions that generate much coordination/negotiation costs. Due 
Table 3 Transactions under transactions' determinants in preparation stage

\begin{tabular}{|c|c|c|c|c|c|c|}
\hline \multirow[t]{2}{*}{ Determinants } & \multirow[t]{2}{*}{ Sub-determinants } & \multirow[t]{2}{*}{ Transactions under each determinant } & \multicolumn{2}{|c|}{ Groups } & \multicolumn{2}{|c|}{ TCs } \\
\hline & & & $\mathrm{D}$ & $\mathrm{L}$ & I & IV \\
\hline Asset specificity & Information Specificity & $\begin{array}{l}\text { AI1. Information searching for potential } \\
\text { renewal areas }\end{array}$ & $\sqrt{ }$ & $\sqrt{ }$ & $\sqrt{ }$ & - \\
\hline Uncertainty & Institutional Uncertainty & $\begin{array}{l}\text { UI1. Detailed documentation work for } \\
\text { administrative approval/application to } \\
\text { fulfill the institutional requirement }\end{array}$ & $\sqrt{ }$ & $\sqrt{ }$ & - & $\sqrt{ }$ \\
\hline
\end{tabular}

$D$ district government; $L$ local administrative organization; $I$ information searching costs; $I V$ approval costs

to the diverse situation and demands of in-situ residents, reaching an agreement with all insitu residents extremely hard. If the agreements cannot finally be reached, the whole decisionmaking process may be delayed by more than one year, wasting large amounts of resources and time.

\subsection{Level of transactions costs borne by each stakeholder group}

To analyze the level of transaction costs, the relative level of time consumed on each transaction by each stakeholder group is measured. The result is presented by mean scores and summarized with rankings in Table 7. It is shown that except "AR1. Developing/modifying compensation plan and housing expropriation contracts for each residential unit", all other transactions are experienced by more than one stakeholder group. Overall, for four key stakeholder groups, most of their top 3 time-consuming transactions generate negotiation/coordination costs. Among these high-ranking transactions, "UB4. Conducting mass work, such as propaganda, public hearing, one-to-one talks, etc. to avoid social contradiction" and "AR2. Coordination and negotiation with in-situ residents to reach agreements on compensation plan and housing expropriation contracts" are the top two of both district government and local administrative organizations. These two transactions share two commonalities. One is that they both refer to the coordination/negotiation with in-situ residents, and the other is they both occur in the final stage of the decision-making process. "UB1. Coordination between different stakeholder groups to avoid misconstruction and build mutual trust" is the only transaction rank the top 4 of all four stakeholder groups. Different from the above two, this transaction occurs in three decision-making stages (except for the first stage). Given consulting parties, besides coordination/negotiation costs, the top 3 time-consuming transactions also relate to lots of research costs, which is different from all the other stakeholder groups. The result also indicates that the district government bears the transaction costs generated by all 19 identified transactions. On the contrary, the municipal government experiences the minimum number of transactions (8 out of 19) among the four stakeholder groups. Consulting parties spend their time on 13 transactions, and the mean score of these 13 transactions is higher than all others. 


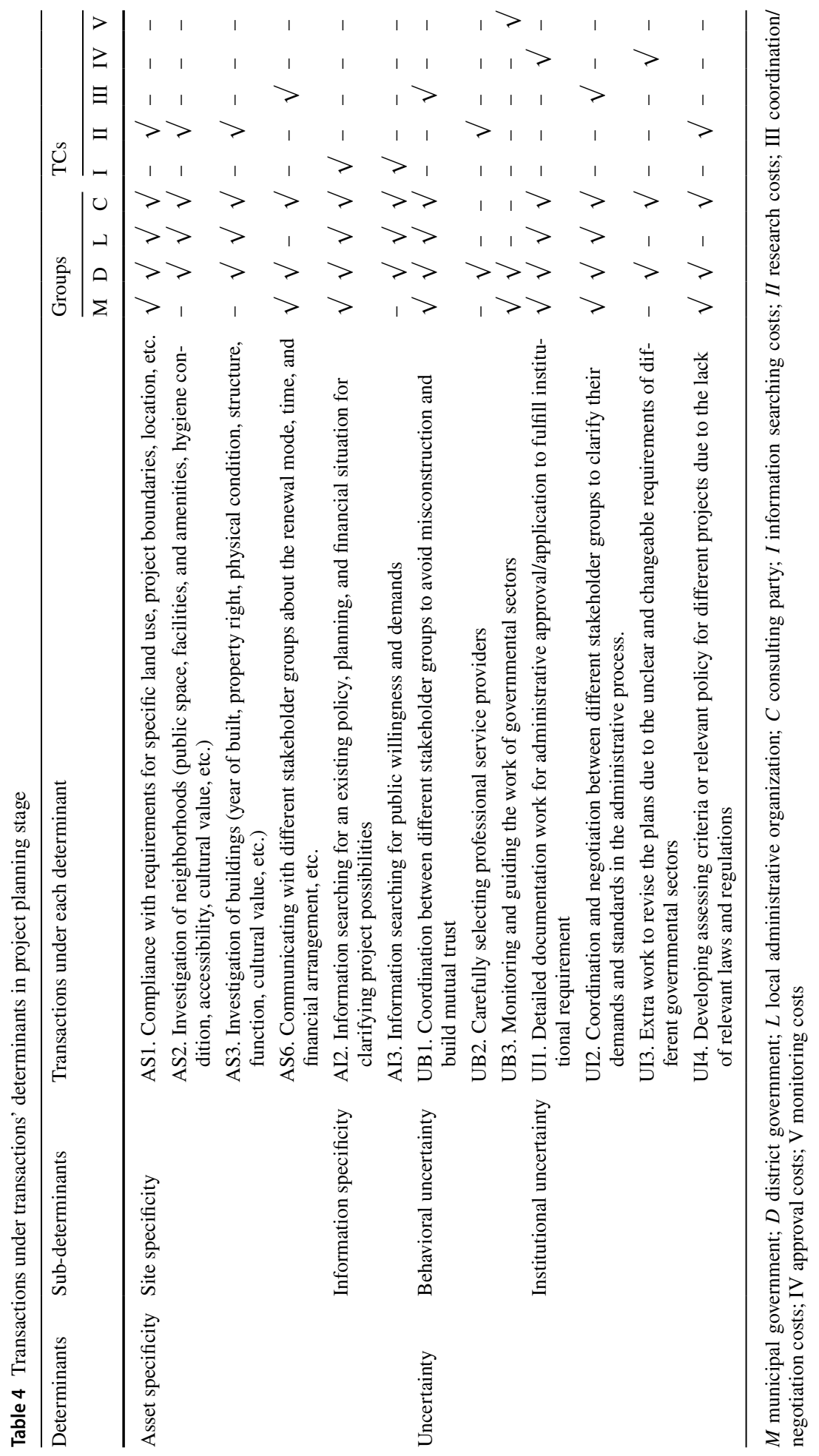




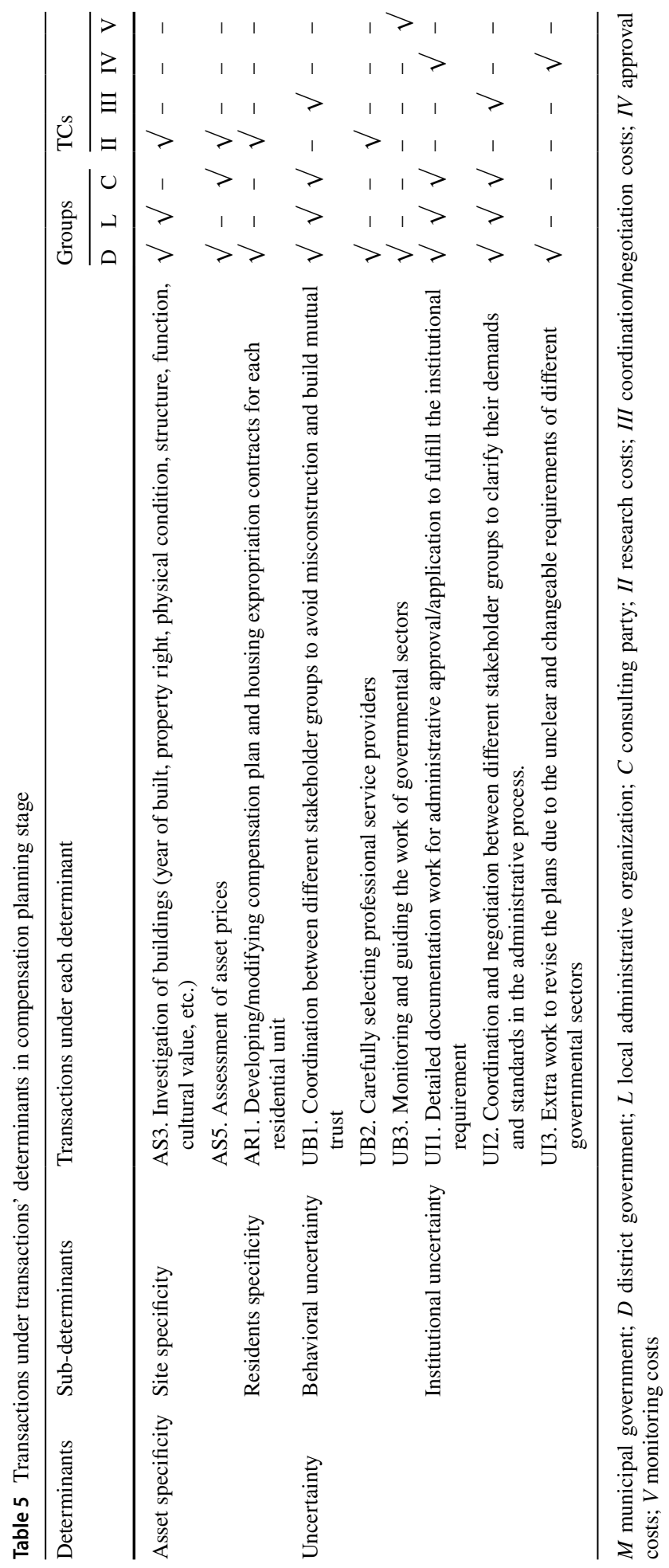




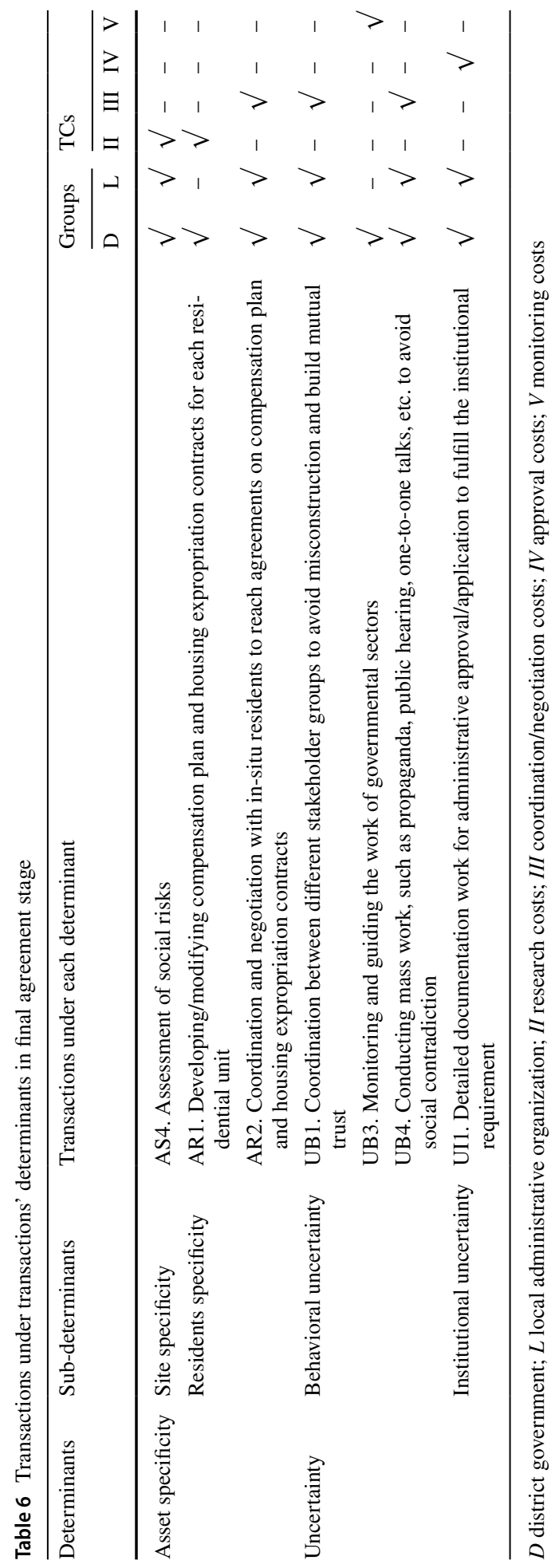




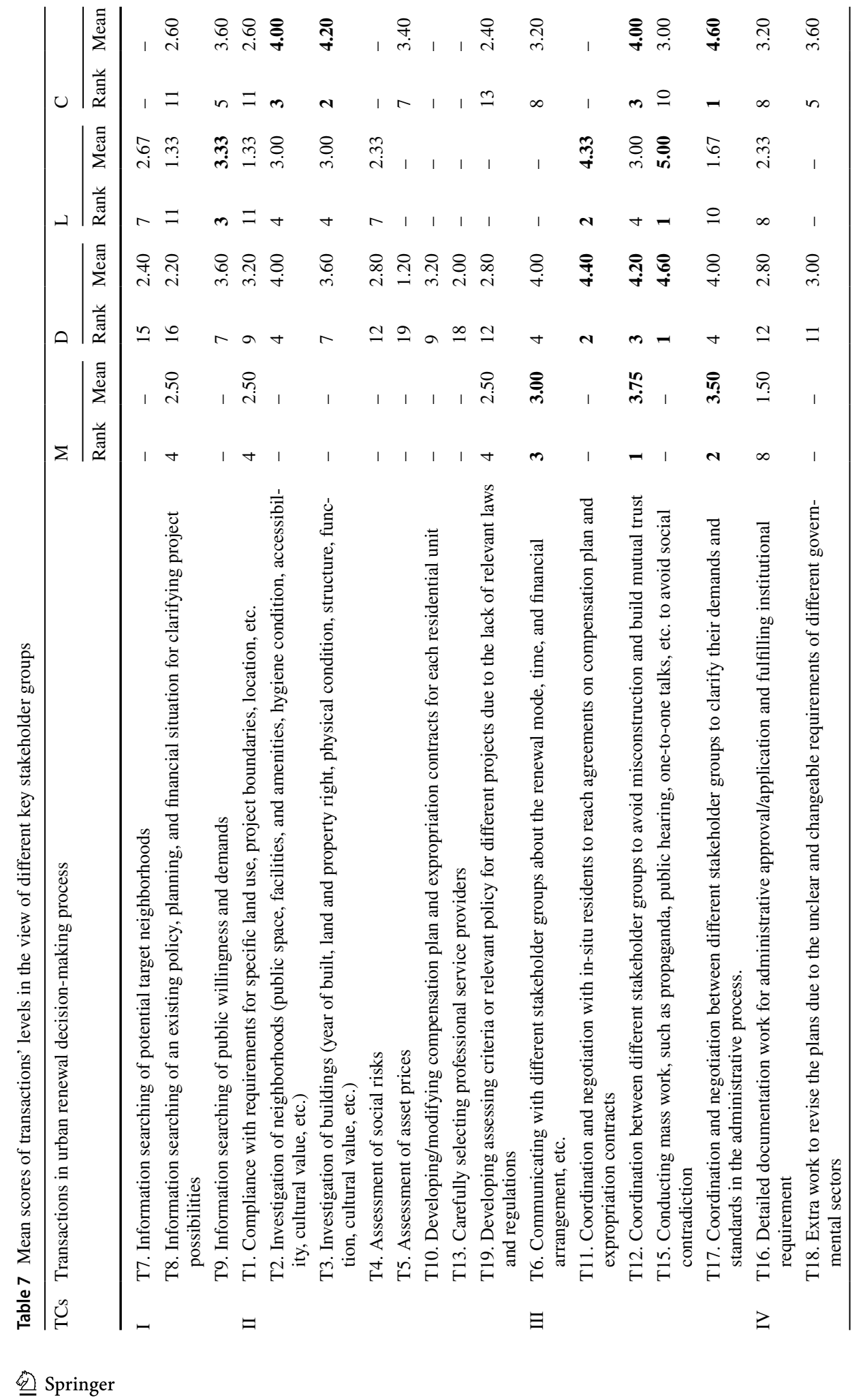




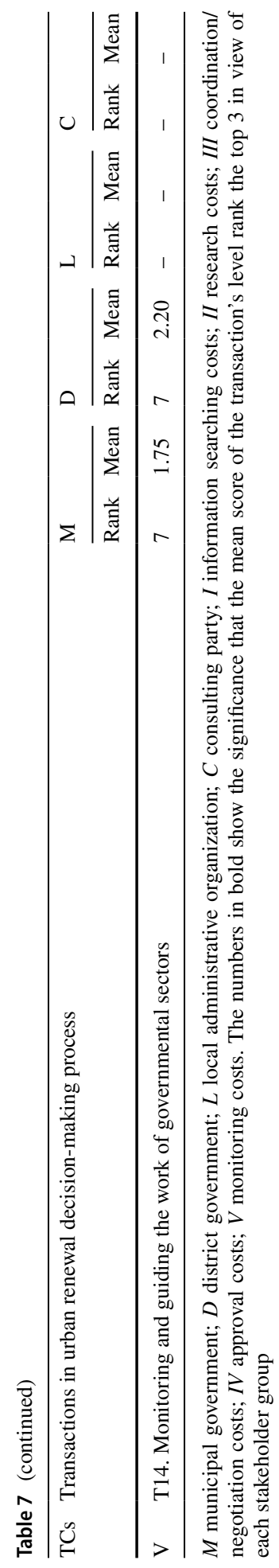




\section{Discussions}

\subsection{Uneven distribution of transaction costs}

In many government-initiated public projects, the institutional design ignores transaction costs incurred before the implementation process (Alexander 2001; Shahab et al. 2018). As it is clearly shown in the findings, the decision-making process of urban renewal is full of transaction costs. Moreover, the distribution of transaction costs is uneven, given not only decision-making stages but also stakeholder groups who bear the costs.

Essentially, the working quality of first two decision-making stages (developing project plan) is highly relevant to the barriers of the last two (reaching agreement on copmensation plan). However, the transaction costs in the former two stages are much less than the latter. Moreover, given the last two stages, the quality of compensation planning (third stage) is decisive to the work difficulty in reaching agreements on the plan (fourth stage). However, similarly, the final stage evokes most of the transaction costs than the third.

In terms of four key stakeholder groups, the transaction costs they bear are also different from one to another. District government absorbs transaction costs generated by all the identified transactions, followed by consulting parties, local administrative organizations, and municipal government. Although they bear transaction costs differently, all of them complained that they spend too much time on the works, which are indirectly related to their targets and unavoidable. Indeed, it is meaningless to equally distribute transaction costs to every stakeholder group under any condition. Given that the "uneven" is approximately equal to "unfair", a more balanced distribution may reduce the risks and barriers of the project.

\subsection{The domination of negotiation/coordination costs in whole decision-making process}

The urban renewal decision-making process involves many uncertainties, which lead to lots of coordination/negotiation costs. This type of transaction costs plays a dominant role in the whole process borne by every key stakeholder group. One kind of coordination/ negotiation costs is generated in the administrative process. It occurs not only between the four key stakeholder groups but also between many sectors within each group (e.g., different government sectors). There are more than 20 all three levels of government sectors and several consulting parties in different fields involving in and taking different responsibilities. Based on current regulations, different sectors in the district government can initiate and coordinate the work for a different type of urban renewal projects. For example, Commission of Construction is responsible for shanty town redevelopment; Bureau of Urban Planning control the renewal in designated townscape region; Bureau of Housing Management manage the projects in typical dilapidated neighborhoods and buildings. No matter which sector coordinates the project, it requires the active cooperation of more than ten other sectors and consulting parties. Under current regulation, in district government, there is no single sector can fully administrate urban renewal, and in municipal government, sectors only deal with the works and documents of corresponding sectors in district government. To complete their tasks, all sectors at different administrative levels have to spend lots of time communicating with many others to discuss the works, clarify their demands and standards, build mutual trust, and avoid misconstruction. 
Another kind of coordination/negotiation cost is generated in communicating with insitu residents (property owners), which occurs in the final step of decision-making. The work needs to be done by both the district government and local administrative organizations to persuade hundreds or thousands of residents to understand and agree on the compensation plan made by the government. However, normally, there are scores of in-situ residents not satisfying with the plan in the aspect of property legality, ownership, registered building space and structure, compensation standard, etc. In many cases, some residents even insist on an excessive compensation price, which is several times the market price. Because maintaining social stability is one top concern of all levels of government, plenty of time will be spent to achieve the final agreements and minimize the risk of social contradiction. As it is stated by interviewee L2: "To resolve the issue, rounds of negotiation and coordination should be done with almost every dissatisfied property owner. However, most of them held a biased perception of the government. To improve their understanding of the government's works and persuade them to agree on the plan, many grass-rooted civil servants visit their home day by day. In many circumstances, the civil servants even contact the property owners' relatives and friends to help with the persuasion."

\subsection{Imperfect institution of urban renewal decision-making}

Based on the findings, it can be clearly stated that the current institution of urban renewal decision making is imperfect. First, the first two stages and the last two are strictly separated. When the project plan (designated renewal area, time plan, renewal mode, financing arrangement, etc.) is made and approved, the related sectors must follow it, and continue developing a compensation plan for expropriation then try to reach an agreement with insitu residents. In principle, there is no feedback loop between the second and third stages. Therefore, even if the last two stages do not go well (e.g., too many in-situ residents refuse to move out), all governmental sectors need to do is to push the agenda on the last two stages to reach a final agreement, even if it will cause tremendous transaction costs. Moreover, the strict separation of decision-making stages also creates a loophole for in-situ residents to obtain more benefits. Since there may be many projects being planned in the short term, it is possible to be a long time before the compensation plan is made in one renewal area. Thus, as D3 states it: "To gain more compensation, in-situ residents may rush to construct unapproved buildings with low costs and low quality during the gap period, such as constructing one more floor on the old buildings." It indirectly increases research costs and coordination/negotiation costs borne by the district government. Furthermore, the second and third stage both requires the investigation of buildings. The former investigates the physical condition, function, cultural value of the buildings, and the latter investigates the land/property right, building structure, and legality. The separation of stages also results in the separation of building investigation, thus generate more research costs.

Second, there is a lack of guidance on project planning, which arouses uncertainties and further induces transaction costs. Under current regulations, the purpose and elements of a project plan are clear to all stakeholder groups, but how to make the project plan is not explicit. Therefore, plan making is restricted by many aspects. Today, different types of urban renewal projects are initiated and led by different sectors in the district government. Each sector has its expertise and institution and requires consulting parties in a different background, such as urban development, industrial development, social management, spatial planning, etc. Nevertheless, most specific sectors or consultants are only specialized in their fields. Without a holistic view on urban renewal, it arouses uncertainties and further 
induces transaction costs, thus raising the risks of projects. Also, without clear guidance on how to make a project plan, the works of all stakeholder groups can only rely on the existing plans, policies, and specific requirements of various relevant sectors. These may pose more restrictions than instructions, or even contradict each other. It may generate lots of research costs and coordination/negotiation costs in project planning.

Third, there is a lack of a cross-sector cooperation mechanism, which is the primary cause of high-level coordination/negotiation costs. The urban renewal project plan is seen as the bottom-level plan; stakeholders have to comply with much high-level government planning, such as urban planning, land use planning, national economic and social development planning, etc. Moreover, in different sites, different sectors have their requirements and restrictions (e.g., cultural heritage, landscape, state-owned properties, etc.). In many circumstances, one sector may look for cooperation only when it needs supports, or others' works are against its requirements. When an issue involves many sectors, the cooperation may become more complicated and cause misunderstandings and conflicts. Thus, much time will be wasted on the coordination and negotiation activities in the whole process without a mature cross-sector cooperation mechanism.

\subsection{Recommendations to reduce transaction costs}

Some policy implications are provided to reduce transaction costs identified above. First, it is of great importance for the district government to establish a specific approach of urban renewal planning to replace the current project planning. It provides strict guidelines on how to designate urban renewal areas and plan the renewal mode, time, financial arrangement, and other relevant elements (e.g., management, and post-maintenance). It introduces the detailed multi-disciplinary requirements of research and consultation work, including urban development, spatial planning, social management, cultural value assessment, building assessment, etc. to ensure the plan is made in a comprehensive view. Moreover, the approach clearly illustrates the relationships between this urban renewal planning and other related policies, planning, regulations, and requirements of specific sectors to reduce the restrictions in plan making.

To avoid the uneven distribution of transaction costs, it is suggested to abolish the strict separation of project planning and compensation planning and establishing a feedback loop in the whole decision-making process. Combining the second (project planning) and third stages (compensation planning), or even integrating compensation planning into urban renewal planning, can save much time and resources on building an investigation. In addition, it greatly reduces the gap period and avoids in-situ residents to build unapproved buildings for more compensation. Furthermore, it may also indirectly improve the quality of plan making, thus reduce the burden of district government and local administrative organizations in dealing with in-situ residents.

To reduce the high-level coordination/negotiation costs, governments can establish a cooperation mechanism for different participants (including in-situ residents). This implies a platform for all participants to cooperatively cope with complex problems in urban renewal, ensuring their expectations, knowledge, and information are well-considered and presented. Based on this cooperation mechanism, all relevant sectors in different levels of government, consulting parties, in-situ residents, and other organizations can know when and how to provide their information, knowledge, and resources. If necessary, establishing a leading sector to take responsibility for all relevant issues in urban renewal can also include in the mechanism. Taking two Asian counterparts, Hong Kong and Singapore as 
examples, most issues relevant to urban renewal are responsible by one sector (namely, the Urban Renewal Authority in Hong Kong, and Urban Redevelopment Authority in Singapore) (Law et al. 2009). By setting up a focused authority, it will be much easier to coordinate with other participants and thus significantly reduce transaction costs.

\section{Conclusions}

The study reported in this paper adopts transaction costs theory to probe the decisionmaking process of urban renewal in Chongqing, China. It indicates that transaction costs theory appears fruitful to better understand the decision-making process in Chinese urban contexts, from New Institutional Economics perspective. This paper takes the central urban districts in Chongqing as the study area and identifies four main stages in urban renewal decision-making: the preparation stage, the project planning stage, the compensation planning stage, and the final agreement stage. This study focuses on the stakeholder groups of municipal government, district government, local administrative organizations, and the consulting parties, who are highly and actively involved in the administrative process. Based on the literature review, an analytical framework is established to identify and analyze transaction costs borne by different stakeholder groups in the whole decision-making process. The results show that there exist many transaction costs in the administrative process of urban renewal decision-making. The distribution is uneven in terms of different stages and stakeholder groups. Moreover, the negotiation/coordination costs account for the significant part of the total transaction costs. The primary cause of high-level transaction costs is the current institutions of urban renewal decision-making, including the strict separation of decision-making stages, the lack of guidance on project planning, and the lack of cross-sector cooperation mechanism. To reduce transaction costs, it requires the abolishment of strict-separated stages, the establishment of a specific approach of urban renewal planning, a new cooperation mechanism, and a focused urban renewal authority.

By presenting an empirical study, this paper provides theoretical discussions on applying transaction costs theory in the urban renewal decision-making process. Accordingly, it presents policy implications to reduce transaction costs and tackle institutional problems in China. However, collecting data by interviewing individuals may bring about more subjective factors to the result. Moreover, focusing on stakeholder groups highly participating in administrative activities cannot fully evaluate the whole system. These need to be acknowledged, and it will be of benefit to combine more quantitative methods and explore a broader range of stakeholder groups in future studies.

Acknowledgements This work is supported by the China Scholarship Council and the Delft University of Technology. The second author is grateful for the Delft Technology Fellowship (2014-2019) for its generous funding support.

Open Access This article is licensed under a Creative Commons Attribution 4.0 International License, which permits use, sharing, adaptation, distribution and reproduction in any medium or format, as long as you give appropriate credit to the original author(s) and the source, provide a link to the Creative Commons licence, and indicate if changes were made. The images or other third party material in this article are included in the article's Creative Commons licence, unless indicated otherwise in a credit line to the material. If material is not included in the article's Creative Commons licence and your intended use is not permitted by statutory regulation or exceeds the permitted use, you will need to obtain permission directly from the copyright holder. To view a copy of this licence, visit http://creativecommons.org/licenses/by/4.0/. 


\section{References}

Alexander, E. R. (2001). A transaction-cost theory of land use planning and development control: Towards the institutional analysis of public planning. Town Planning Review, 72, 45-76.

Arrow, K. (1969). The analysis and evaluation of public expenditure: The PPB system. Washington DC: Government Printing Office.

Buitelaar, E. (2004). A transaction-cost analysis of the land development process. Urban Studies, 41, 2539-2553.

Chen, H., Jia, B., \& Lau, S. (2008). Sustainable urban form for Chinese compact cities: Challenges of a rapid urbanized economy. Habitat International, 32, 28-40.

Cheung, S. N. (1989). Economic organization and transaction costs (pp. 77-82). Allocation: Information and Markets.

Cho, C.-J. (2011). An analysis of the housing redevelopment process in Korea through the lens of the transaction cost framework. Urban Studies, 48, 1477-1501.

Chung, L. L. W. (1994). The economics of land-use zoning: A literature review and analysis of the work of Coase. Town Planning Review, 65, 77.

Coggan, A., Buitelaar, E., Whitten, S., \& Bennett, J. (2013). Factors that influence transaction costs in development offsets: Who bears what and why? Ecological Economics, 88, 222-231.

Coggan, A., Whitten, S. M., \& Bennett, J. (2010). Influences of transaction costs in environmental policy. Ecological Economics, 69, 1777-1784.

CSB. (2017a). Chongqing Statistical Bulletin for Economic and Social Development. http://jtj.cq.gov.cn/ $\mathrm{html} / \mathrm{tj} j \mathrm{j} / \mathrm{tjgb} /$.

CSB. (2017b). Chongqing Statistical Yearbook. http://www.cqtj.gov.cn/tjnj/2017/zk/indexce.htm.

Enserink, B., \& Koppenjan, J. (2007). Public participation in China: Sustainable urbanization and governance. Management of Environmental Quality: An International Journal, 18, 459-474.

Fan, K., Chan, E. H., \& Qian, Q. K. (2018). Transaction costs (TCs) in green building (GB) incentive schemes: Gross floor area (GFA) concession scheme in Hong Kong. Energy Policy, 119, 563-573.

Garrick, D., McCann, L., \& Pannell, D. J. (2013). Transaction costs and environmental policy: Taking stock, looking forward. Ecological Economics, 88, 182-184.

Hastings, E., \& Adams, D. (2005). Facilitating urban renewal: Changing institutional arrangements and land assembly in Hong Kong. Property Management, 23, 110-121.

Jiang, J., et al. (2012). Urban renewal and practice in China. Shandong: Shandong University Press.

Juan, Y.-K., Roper, K. O., Castro-Lacouture, D., \& Ha Kim, J. (2010). Optimal decision making on urban renewal projects. Management Decision, 48, 207-224.

Lai, Y., \& Tang, B. (2016). Institutional barriers to redevelopment of urban villages in China: A transaction cost perspective. Land Use Policy, 58, 482-490.

Law, C., et al. (2009). Study report-urban renewal policies in Asian cities for the urban renewal strategy review. Development Bureau, HKSAR Government.

Lee, G. K., \& Chan, E. H. (2008). The analytic hierarchy process (AHP) approach for assessment of urban renewal proposals. Social Indicators Research, 89, 155-168.

Li, X., Kleinhans, R., \& van Ham, M. (2018). Shantytown redevelopment projects: State-led redevelopment of declining neighbourhoods under market transition in Shenyang, China. Cities, 73, 106-116.

Li, T. H., Ng, S. T., \& Skitmore, M. (2012). Public participation in infrastructure and construction projects in China: From an EIA-based to a whole-cycle process. Habitat International, 36, 47-56.

Liao, Y. (2013). A study of urban regeneration based on multi-stakeholder partnership Governance. Chongqing: Chongqing University.

Liu, G., Xu, K., Zhang, M., \& Zhou, T. (2012). A study on the life-span of demolished buildings: Based on the investigation of demolished buildings in Chongqing. Urban Studies, 19, 109-112.

Liu, G., Yi, Z., Zhang, X., Shrestha, A., Martek, I., \& Wei, L. (2017). An evaluation of urban renewal policies of Shenzhen, China. Sustainability, 9, 1001.

Maginn, P. J. (2007). Towards more effective community participation in urban regeneration: The potential of collaborative planning and applied ethnography. Qualitative Research, 7, 25-43.

Mayer, I. S., van Bueren, E. M., Bots, P. W., van der Voort, H., \& Seijdel, R. (2005). Collaborative decisionmaking for sustainable urban renewal projects: A simulation-gaming approach. Environment and Planning B: Planning and Design, 32, 403-423.

McCann, L. (2013). Transaction costs and environmental policy design. Ecological Economics, 88, 253-262.

Mettepenningen, E., Van Huylenbroeck, G. (2009). Factors influencing private transaction costs related to agri-environmental schemes in Europe, Multifunctional rural land management: Economics and policies (pp. 145-168). 
Michaelowa, A., \& Jotzo, F. (2005). Transaction costs, institutional rigidities and the size of the clean development mechanism. Energy Policy, 33, 511-523.

Mundaca, T. L., Mansoz, M., Neij, L., \& Timilsina, G. R. (2013). Transaction costs analysis of lowcarbon technologies. Climate Policy, 13, 490-513.

North, D. C. (1990). A transaction cost theory of politics. Journal of Theoretical Politics, 2, 355-367.

Qian, Q. K. (2010). Government's roles and measures needed in China for promoting building energy efficiency (BEE). International Journal of Construction Management, 10, 119-138.

Qian, Q. K., Chan, E. H., \& Choy, L. H. (2012). Real estate developers' concerns about uncertainty in building energy efficiency (BEE) investment-A transaction costs (TCS) perspective. Journal of Green Building, 7, 116-129.

Qian, Q. K., Chan, E. H., Visscher, H., \& Lehmann, S. (2015). Modeling the green building (GB) investment decisions of developers and end-users with transaction costs (TCs) considerations. Journal of Cleaner Production, 109, 315-325.

Shahab, S., Clinch, J. P., \& O’Neill, E. (2018). Accounting for transaction costs in planning policy evaluation. Land Use Policy, 70, 263-272.

Shen, L., Yuan, H., \& Kong, X. (2013). Paradoxical phenomenon in urban renewal practices: Promotion of sustainable construction versus buildings' short lifespan. International Journal of Strategic Property Management, 17, 377-389.

Tang, J. (2015). Analysis of the pros and cons of urban renewal governance: The comparison of urban renewal institution of Guangzhou. Shenzhen and Foshan, Planners, 5, 46-53.

Tang, B.-S., Wong, S.-W., \& Lau, M. C.-H. (2008). Social impact assessment and public participation in China: A case study of land requisition in Guangzhou. Environmental Impact Assessment Review, 28, 57-72.

Tian, L. (2009). Analysis of urban renewal policy-making mechanismin in China Shandong University.

Wang, H., Shen, Q., Tang, B.-S., Lu, C., Peng, Y., \& Tang, L. (2014). A framework of decision-making factors and supporting information for facilitating sustainable site planning in urban renewal projects. Cities, 40, 44-55.

Williamson, O. E. (1985). The economic institutions of capitalism. New York: Free Press.

Williamson, O. E. (1991). Comparative economic organization: The analysis of discrete structural alternatives. In Administrative science quarterly (pp. 269-296).

Yang, K. (2007). Study on the establishment of an effective mechanism for the Urban Renewal Shandong University.

Yau, Y. S., \& Chan, H. L. (2008). To rehabilitate or redevelop? A study of the decision criteria for urban regeneration projects. Journal of Place Management and Development, 1, 272-291.

Yi, Z., Liu, G., Lang, W., Shrestha, A., \& Martek, I. (2017). Strategic approaches to sustainable urban renewal in developing countries: A case study of Shenzhen, China. Sustainability, 9, 1460.

Zhou, T., Zhou, Y., \& Liu, G. (2017). Key variables for decision-making on urban renewal in China: A case study of Chongqing. Sustainability, 9, 370.

Zhuang, T., Qian, Q. K., Visscher, H. J., \& Elsinga, M. G. (2017). Stakeholders' expectations in urban renewal projects in China: A key step towards sustainability. Sustainability, 9, 1640.

Zhuang, T., Qian, Q. K., Visscher, H. J., Elsinga, M. G., \& Wu, W. (2019). The role of stakeholders and their participation network in decision-making of urban renewal in China: The case of Chongqing. Cities, 92, 47-58.

Publisher's Note Springer Nature remains neutral with regard to jurisdictional claims in published maps and institutional affiliations. 